\title{
De-adoption and exnovation in the use of carotid revascularization: retrospective cohort study
}

\author{
Kimon Bekelis, ${ }^{1}$ Jonathan Skinner, ${ }^{1,2}$ Daniel Gottlieb, ${ }^{1}$ Philip Goodney ${ }^{1,3}$
}

${ }^{1}$ The Dartmouth Institute for Health Policy and Clinical

Practice, One Medical Center Drive, Lebanon, NH 03755, USA

${ }^{2}$ Department of Economics, Dartmouth College, Hanover, $\mathrm{NH}$, USA

${ }^{3}$ Section of Vascular Surgery, Dartmouth-Hitchcock Medical Center, Lebanon, NH, USA

Correspondence to: K Bekelis kbekelis@gmail.com

Additional material is published online only. To view please visit the journal online.

Cite this as: $B M J$ 2017;359:j4695 http://dx.doi.org/10.1136/bmj.j4695

Accepted: 4 October 2017

\section{ABSTRACT}

OBJECTIVE

To determine physician characteristics associated with exnovation (scaling back on use) and de-adoption (abandoning use) of carotid revascularization.

\section{DESIGN}

Retrospective longitudinal cohort study.

SETTING

Medicare claims linked to the Doximity database provider registry, 2006-13.

\section{PARTICIPANTS}

9158 physicians who performed carotid revascularization on Medicare patients between 2006 and 2013.

\section{MAIN OUTCOME MEASURES}

The primary outcomes were the number of carotid revascularization procedures for each physician per year at the end of the sample period, and the percentage change in the volume of carotid revascularization procedures.

\section{RESULTS}

At baseline (2006-07), 9158 physicians performed carotid revascularization. By 2012-13 the use of revascularization in this cohort had declined by $37.7 \%$, with two thirds attributable to scaling back (exnovation) rather than dropping the procedure entirely (de-adoption). Compared with physicians with fewer than 12 years of experience, those with more than 25 years of experience decreased use by an additional $23.0 \%$ (95\% confidence interval $-36.7 \%$ to $-9.2 \%)$. The lowest rates of decline occurred in physicians specializing in vascular or thoracic surgery, for whom the procedures accounted for a large share of revenue. Physicians with high proportions of patients aged more than 80 years or

\section{WHAT IS ALREADY KNOWN ON THIS TOPIC}

Diffusion, or the process by which innovations enter everyday use, has been studied extensively in many disciplines, with a particularly strong focus on how new medical technologies spread across hospitals and health professionals Despite extensive research on factors that contribute to diffusion, the process by which physicians scale back the use of medical practices is limited Previous researchers have indicated that de-adoption (abandoning use) and exnovation (scaling back use) by physicians are inherently slow processes with distinct characteristics that do not conform under known diffusion models

\section{WHAT THIS STUDY ADDS}

Using the example of carotid revascularization, important differences in rates of exnovation were found depending on the characteristics of the physician

Those physicians who readily accept change in medical practice are likely to be more experienced than those less ready to accept change, whereas late exnovators are in interventional specialties such as vascular surgery and thoracic surgery in which these procedures comprise a larger share of practice with asymptomatic carotid stenosis were less likely to reduce their use of carotid revascularization.

\section{CONCLUSION}

Surgeons with more experience and the lowest share in carotid revascularization practice reduced their use of the procedure the most. These practice factors should be considered in quality improvement efforts when the evidence base evolves away from a specific treatment.

\section{Introduction}

Diffusion, or the process by which innovations enter everyday use, has been studied extensively in many disciplines, with a particularly strong focus on how new medical technologies spread across hospitals and health professionals. Despite extensive research on factors that contribute to diffusion, the process by which physicians scale back the use of medical practice has received much less attention, in part because there has been no consistent nomenclature to identify this process in medical care and in other technologies. ${ }^{1-6}$

More recently, studies have begun to focus on factors affecting rates of abandonment or "deadoption" by physicians of a procedure that has been found to be harmful or replaced by a better alternative. ${ }^{2}$ In this study we distinguish between de-adoption and "exnovation," which is scaling back but not necessarily abandoning a practice. This term comes from the environmental science literature, ${ }^{7}$ management, ${ }^{8-10}$ public policy, ${ }^{11}$ and health services research, ${ }^{5} 12$ although the earlier literature sometimes conflates exnovation and de-adoption. We hypothesized that the process by which healthcare providers drop existing practices is likely to be very different from the process of adopting or diffusing new and less familiar treatments. ${ }^{14}$ Previous researchers have indicated that de-adoption and exnovation by physicians are inherently slow processes with distinct characteristics that do not conform under known diffusion models. ${ }^{2-14}$

Several things may explain why physicians would reduce or drop a treatment. ${ }^{14}$ As a process, it may be related to the emergence of evidence that established healthcare practices previously considered innovative are harmful, ineffective, or disruptive. ${ }^{615-18}$ On the contrary, it may simply occur when new or competing procedures are adopted. ${ }^{6}{ }^{15-8}$ Several investigators have hypothesized that provider level factors such as education, practice setting, or revenue stream, play a central role, especially in settings where clinical interventions have uncertain medical benefits. ${ }^{6}$ 14-18 Understanding the process by which clinicians deadopt or exnovate, and whether such reductions 
are based on clinical evidence or the organizational structure or training of the physician, is important for reducing low value treatments in everyday clinical practice.

An example of exnovation can be found in the recent decline in use of carotid revascularization, ${ }^{19} 20$ which, since its introduction in the 1970s, has been controversial. Use of the procedure has been particularly sensitive to evolving medical evidence, especially to randomized trials comparing its effectiveness with medical management. ${ }^{21-25}$ This responsiveness to outside influence makes it a good example to study what causes physicians to scale back. To better understand factors that contribute to the process of exnovation, we utilized a unique dataset on physician training, experience, publications, funded research, and sex from the Doximity database on all physicians in the United States. We then linked these to US Medicare claims data for carotid revascularization during 2006-13. This unique dataset was used to describe the process of de-adoption and exnovation and to identify contributory factors.

\section{Methods}

\section{Analytic overview}

Initially we created a dataset of all providers who performed carotid revascularization procedures, either carotid endarterectomy or carotid artery stenting, within fee-for-service Medicare claims between 1 January 2006 and 31 December 2013. We then matched these physicians to their respective files in Doximity, a large registry of physician training, practice, and personal educational characteristics. After creating these matched files, we determined associations between physician characteristics and exnovation for carotid revascularization between 2006 and 2013.

\section{Medicare cohort}

We used $100 \%$ of the Medicare Denominator file (patient characteristics) and corresponding MedPAR (hospital billing claims), and Carrier files (physician billing claims), for 2006-13 to select patients who underwent carotid revascularization, using current procedural terminology codes (medical code set used to report medical, surgical, and diagnostic procedures and services) for carotid endarterectomy or carotid artery stenting (see supplementary table S1). Reimbursement for procedures based on current procedural terminology codes is the same across specialties and did not change over the years of the study. To be included in the cohort, the physician must have submitted at least one Medicare bill during each year from 2006 to 2013 and have performed at least one carotid revascularization (to create a comprehensive cohort) during the baseline period 2006-07.

Using the National Provider Identifier (NPI) available on these claims, we assigned to each physician the total number of carotid endarterectomy and carotid artery stenting procedures performed in each calendar year.

\section{Medicare-Doximity link}

Doximity is a cross sectional database that provides online networking services for US physicians. ${ }^{26}$ As of 10 November 2014 the database included 1005419 physicians. Doximity draws on several sources of information to identify physicians, including the national plan and provider enumeration system NPI registry, self registered members without active NPIs (ie, physicians with medical degrees who have not practiced), and physicians without NPIs who are employed by collaborating institutions that provide information to the company (eg, researchers or administrators who have not practiced, and therefore do not have an NPI but work at an institution that provides information on its employees or alumni of the company, or both).

Physicians were first classified based on their reported specialty in Medicare claims (cardiology, general surgery, neurosurgery, radiology, thoracic surgery, vascular surgery). We then matched each individual physician with his or her corresponding characteristics from the Doximity database. We matched $100 \%$ of those physicians who performed carotid revascularizations in Medicare claims to their records in Doximity. In cases of disagreement about the designated specialty between Medicare and Doximity records, we favored Doximity. From Doximity we extracted physician characteristics, practice setting, and experience. The American Medical Association has published the total number of physicians per specialty in the country. ${ }^{5}$

\section{Outcome measures}

The primary outcomes were the number of carotid revascularization procedures for each physician per year at the end of the sample period, and the percentage change in the volume of carotid revascularization procedures. To improve statistical precision, we defined the baseline volume of carotid revascularizations as the average of the yearly volume at the physician level during 2006 and 2007, and the ending volume was similarly defined as the average yearly volume in 2012 and 2013. We calculated the percentage change by dividing the change in carotid revascularization procedures (volume at the end of the study minus baseline volume) by the baseline volume of carotid revascularization.

If the physician simply stopped performing carotid revascularization, the percentage change would be $-100 \%$, and they would be assumed to have deadopted the procedure; physicians who continued to perform the procedure were exnovators. We acknowledge that our estimate of de-adopters is biased downward if the physicians cease treating Medicare patients but continue to treat commercially insured patients not in our data.

\section{Exposure variables}

We extracted physician characteristics from the linked Doximity-Medicare dataset. Physician group size (a factor with considerable impact on previous 
diffusion studies) was calculated using the taxpayer identification number and divided into three categories (single physician, 2-19 physicians, >20 physicians). Physician experience was divided into three categories ( $<12$ years, 13-24 years, and $>25$ years). Doximity provided these cut-offs. Group size was selected because of evidence in the literature that larger groups promote diffusion. Experience in a skill driven specialty such as surgery is the equivalent of education in classic diffusion studies. The categorical variables were participation in clinical trials (as a proxy for academic activity), physician specialty (vascular surgery, thoracic surgery, general surgery, neurosurgery, interventional cardiology, interventional radiology), and physician sex. We included the number of publications by physicians as a proxy of their academic productivity. Our hypothesis from previous models of diffusion was that academically active physicians would be more likely to scale their practices based on published evidence.

For the entire period we additionally recorded the percentage of each physician's patients who were aged more than 80 years and the percentage of patients with symptoms (operated on within six months of an ischemic stroke or transient ischemic attack) and asymptomatic patients treated by each physician. To adjust for providers approaching retirement and scaling down their practice, we calculated the percentage change in total number of all surgical procedures in Medicare for each physician and the percentage change in total Medicare Part B expenditures billed by each physician during the study period. For each provider we calculated the practice share of carotid revascularization by dividing the total number of carotid revascularization procedures by the total number of procedures performed by that provider, all calculated at baseline. We defined regional (state level) rates of carotid disease (atherosclerosis) in the overall Medicare population during the years of the study using ICD-9 (international classification of diseases, ninth revision) codes (see supplementary table S1). We used this variable to adjust for state level changes over time in the underlying burden of carotid disease that might have an independent impact on the demand for revascularization.

\section{Statistical analysis}

To investigate the association between reduction in use of carotid revascularization and physician or practice characteristics, we used three multivariable regression models. We controlled for several covariates in all analyses: physician group size, years of experience, change in total number of procedures, participation in clinical trials, number of publications, physician specialty, and physician sex. To simplify the statistical analysis, we focused primarily on the change in volume of revascularizations rather than considering de-adoption and exnovation separately.

In the first specification, which was based on a linear model, we sought to explain the percentage change in the volume of carotid revascularizations between
2006-07 and 2012-13. This analysis controlled for physician group size, years of experience, participation in clinical trials, number of publications, percentage change in total number of all procedures performed by the physician (or percentage change in total Medicare Part B expenditures billed by each physician in sensitivity analysis), percentage change in the regional prevalence of carotid disease, and physician sex.

The second specification used a non-linear approach that assumed a Poisson distribution for the number of carotid revascularizations in 2012-13, controlling for the baseline number of carotid revascularizations in 2006-07, physician group size, years of experience, participation in clinical trials, number of publications, percentage change in total number of all procedures performed by the physician (or percentage change in total Medicare Part B expenditures billed by each physician in sensitivity analysis), percentage change in the regional prevalence of carotid disease, physician specialty, and physician sex. Reported coefficients are identical when we use average counts rather than total counts in the Poisson estimation procedure.

The final specification was similar to the second Poisson model but included two additional variables: the fraction of patients requiring carotid revascularization who were aged more than 80 years and the fraction of asymptomatic patients. Because recent guidelines ${ }^{27}$ have raised concerns about performing carotid revascularization in asymptomatic patients or in those aged more than 80 years, we hypothesized that physicians with larger shares of such patients will experience the most rapid decline in number of carotid revascularizations performed.

We conducted additional statistical tests to better understand why some physicians scaled back on carotid revascularization more rapidly than others. For example, perhaps specialties for which carotid revascularizations represented the largest share of revenue would be least likely to reduce usage. ${ }^{28}$ To test this hypothesis, we considered the correlation between the 2006-07 average share of Medicare billing derived from carotid revascularization and the percentage change in volume of carotid revascularization procedures between 2006-07 and 2012-13, both aggregated at the specialty level.

To rule out the possibility that differences in rates of exnovation across physicians simply reflected shifting of patients (for example, some specialists altering their practice by sending patients to vascular surgeons instead of performing the procedures themselves), we considered whether states where vascular surgeons (for example) account for a larger market share (the percentage of carotid revascularizations performed by vascular surgeons among all carotid revascularizations in an area) predicted overall changes in utilization rates. Under this "shifting" hypothesis, the share of vascular surgeons should be independent of the overall number of patients receiving treatment. We used a similar empirical strategy to test whether experienced surgeons might be shifting patients to less experienced surgeons. Under this shifting hypothesis, the state 
level share of carotid revascularizations performed by experienced surgeons should not be associated with differential rates of decline in these procedures.

In additional sensitivity analysis, we excluded retirees (dropping below $1 \%$ of billing for a specialty; see supplementary table S2). Further, to identify whether the two forms of carotid revascularization (carotid endarterectomy and carotid artery stenting) followed different exnovation patterns, we plotted the trends of the two interventions over time (see supplementary figure S1), with a post hoc analysis focusing only on carotid endarterectomy (see supplementary table S3). Our analysis for carotid artery stenting was limited by the small sample size of procedures and is therefore not reported further. We additionally included a year indicator variable for 2010 (the year the Carotid Revascularization Endarterectomy Trial (CREST) was published $)^{29}{ }^{30}$ to identify whether this had an impact on the observed trends in exnovation. We identified no such effect and these results are not reported further. Lastly, to identify the effect of trends in carotid disease on the patterns of exnovation, we investigated whether the percentage change in the regional prevalence of carotid disease correlated with the rates for exnovation of carotid revascularization.

All probability values were the result of two sided tests, and we deemed a P value of less than 0.05 to be significant. Stata version 14 (StataCorp, College Station, TX) and SAS version 9.4 (SAS Institute, Cary, NC) were used for statistical analyses.

\section{Results}

\section{Physician characteristics}

Overall, 9158 unique physicians performed carotid revascularizations on Medicare patients from 2006 to 2013. The specialties of physicians performing the procedures included cardiology $(11.1 \%)$, general surgery $(31.1 \%)$, neurosurgery $(4.0 \%)$, interventional radiology $(17.3 \%)$, vascular surgery $(20.8 \%)$, and thoracic surgery $(15.8 \%)$. Vascular surgeons and thoracic surgeons had the highest practice share of carotid revascularization at baseline among all interventional specialties. Table 1 shows the respective distribution of physician and practice characteristics based on provider specialty.

The percentagechange in total number of procedures was calculated for each physician during the study period to control for providers approaching retirement and scaling down their practice.

\section{Pattern of exnovation}

Figure 1 shows the patterns for exnovation in different specialties. In this cohort of physicians, the use of carotid endarterectomy declined by $37.7 \%$ between 2006-07 and 2012-13. Of the 9019 original physicians performing carotid revascularizations in 2006, 4095 (45.5\%) did not perform any revascularization in 2012-13 and so are considered to have de-adopted. These 4095 physicians accounted for $33.0 \%$ of the total decline in carotid revascularizations, leaving two thirds of the reduction attributed to exnovation.

The largest percentage decline (2006-07 to 201213) in carotid revascularization (table 1) was observed in interventional radiology (73.0\%) and cardiology (77.5\%), whereas vascular surgeons showed the least amount of exnovation (32.3\%), followed by thoracic surgeons (37.7\%). We did not observe a replacement of carotid endarterectomy by carotid artery stenting, since both procedures showed similar rates of decline over the years of the study (see supplementary figure S1).

\section{Characteristics associated with exnovation}

We used a multiple linear regression model, which considered all physician and practice characteristics measured in our dataset (table 2) to identify patient and physician factors associated with combined rates of exnovation and de-adoption. Having more than 25 years of experience (adjusted difference $-15.9 \%, 95 \%$ confidence interval $1.5 \%$ to $33.3 \%$ ) was associated with higher rates of decline compared with practitioners with less than 12 years of experience.

\begin{tabular}{|c|c|c|c|c|c|c|c|}
\hline Characteristics & Total & Cardiology & General surgery & Neurosurgery & $\begin{array}{l}\text { Interventional } \\
\text { radiology }\end{array}$ & Vascular surgery & Thoracic surgery \\
\hline No of physicians & 9158 & $1014(11.1)$ & $2845(31.1)$ & $367(4.0)$ & $1585(17.3)$ & $1904(20.8)$ & $1443(15.8)$ \\
\hline Female sex & $412(4.5)$ & $20(2.0)$ & $156(5.5)$ & $10(2.7)$ & $76(4.8)$ & $120(6.3)$ & $30(2.1)$ \\
\hline Clinical trial participation & $733(8.0)$ & $176(17.4)$ & $54(1.9)$ & $56(15.2)$ & $94(5.9)$ & $228(12.0)$ & $123(8.5)$ \\
\hline $\begin{array}{l}\text { Mean (median and 90th centile) } \\
\text { No of publications }\end{array}$ & $6.7(0,15)$ & $8.5(, 1$ 19) & $2.5(0,4)$ & $23.5(4,74)$ & $4.6(0,10)$ & $10.8(1,32)$ & $6.2(0,14)$ \\
\hline \multicolumn{8}{|l|}{ Experience (years): } \\
\hline$<12$ & 1365 (14.9) & $122(12.0)$ & $424(14.9)$ & $63(17.1)$ & $330(20.8)$ & $293(15.4)$ & $127(8.8)$ \\
\hline $13-24$ & $4460(48.7)$ & $579(57.1)$ & $1186(41.7)$ & 169 (45.9) & $972(61.3)$ & $899(47.2)$ & $658(45.6)$ \\
\hline$\geq 25$ & $3333(36.4)$ & $313(30.9)$ & $1236(43.4)$ & $136(37.0)$ & $284(17.9)$ & $712(37.2)$ & $658(45.6)$ \\
\hline \multicolumn{8}{|l|}{ Group size: } \\
\hline 1 provider & $1584(17.3)$ & $57(5.6)$ & $805(28.3)$ & $48(13.0)$ & $27(1.7)$ & $360(18.9)$ & $287(19.9)$ \\
\hline 2-19 providers & $3828(41.8)$ & $356(35.1)$ & $1251(44.0)$ & $125(34.0)$ & $634(40.1)$ & $748(39.3)$ & $711(49.3)$ \\
\hline$\geq 20$ providers & $3746(40.9)$ & $601(59.3)$ & $789(27.7)$ & $195(53.0)$ & $922(58.2)$ & $796(41.8)$ & $445(30.8)$ \\
\hline$\%$ decline in carotid revascularization & 37.7 & 77.5 & 51.7 & 53.1 & 73.0 & 32.3 & 37.7 \\
\hline $\begin{array}{l}\% \text { decline in carotid revascularization } \\
\text { in patients }>80 \text { years }\end{array}$ & 42.1 & 79.6 & 49.2 & 57.8 & 78.1 & 35.8 & 34.5 \\
\hline
\end{tabular}




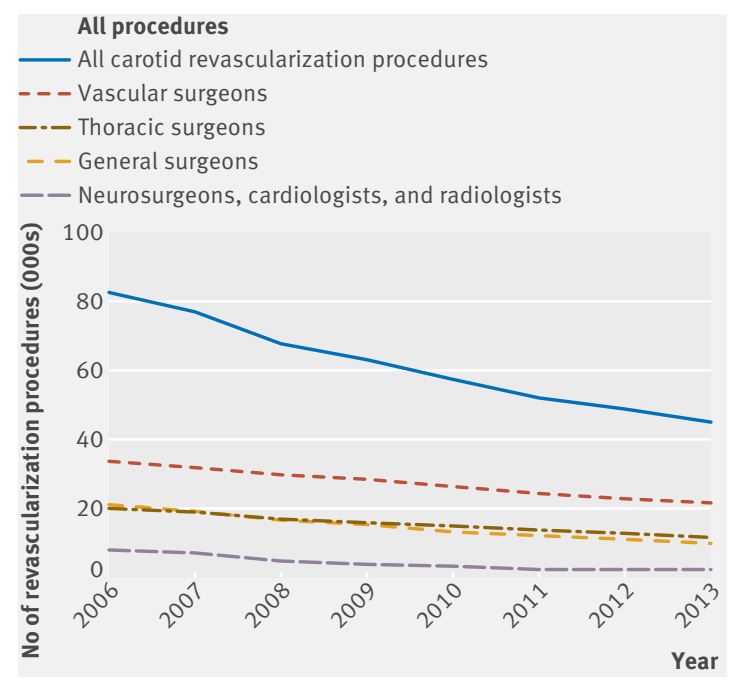

Fig 1 | Annual rates of carotid revascularization procedures in Medicare beneficiaries stratified by specialty, 2006-13

A higher share in specialty practice was strongly and negatively correlated with the rate of reduction $(\mathrm{r}=0.986, \mathrm{P}<0.001$, fig 2$)$. Vascular surgeons with the highest proportion of specialty practice share had the lowest rates of decline. To rule out the possibility that vascular surgeons were simply picking up the additional patients from other specialists, we also found that the share of vascular surgeons (among all surgeons) at the state level was correlated with the overall (state level) decline in rates of carotid revascularization $(\rho=-0.345, \mathrm{P}<0.001)$. To address similar concerns that more experienced surgeons might be passing procedures to less experienced surgeons, we also found that the share of more experienced surgeons (among all surgeons) at the state level was correlated with higher overall (state level) decline in carotid revascularization rates $(\rho=-0.252, \mathrm{P}<0.001)$. Thus, our results cannot be explained solely by the shifting hypothesis in which some physicians hand over their extra patients to others.

We also used a Poisson regression model (table 2) to examine the effect of all prior variables and additionally clinical indications for carotid revascularization, with similar results. Contrary to our first specification, both iterations of the Poisson models we used identified that solo practitioners were more likely to reduce their use of carotid revascularization.

Because recent guidelines ${ }^{27}$ have raised concerns about performing carotid revascularization in asymptomatic patients or those aged more than 80 years, we hypothesized that physicians with larger shares of such patients will experience the most rapid decline in number of carotid revascularizations performed. Physicians with a higher number of patients older than 80 years showed decreased rates of exnovation (risk ratio 3.1, 95\% confidence interval 2.8 to 3.4), whereas minimal association was observed for those providers with a higher number of patients with symptoms (adjusted difference 1.003, 95\% confidence interval 1.001 to 1.005$)$.

Lastly, to identify the effect of trends in carotid disease on patterns of exnovation, we investigated

\begin{tabular}{|c|c|c|c|}
\hline \multirow[b]{2}{*}{ Models } & \multirow{2}{*}{$\begin{array}{l}\text { Adjusted difference }(95 \% \mathrm{Cl}) \\
\% \text { change in carotid revascularization* }\end{array}$} & \multicolumn{2}{|l|}{ Risk ratio $(95 \% \mathrm{Cl})$} \\
\hline & & Final No of carotid revascularizationst & Final No of carotid revascularizationst \\
\hline Female sex & $-9.2(25.4$ to 7.0$)$ & $0.68(0.59$ to 0.78$)$ & $0.70(0.60$ to 0.80$)$ \\
\hline Clinical trial participation & $24.0(-1.7$ to 49.8$)$ & 1.17 (1.06 to 1.30$)$ & 1.18 (1.06 to 1.30$)$ \\
\hline Publications & $8.3(-8.4$ to 25.0$)$ & $0.86(0.73$ to 1.02$)$ & $0.87(0.74$ to 1.03$)$ \\
\hline \multicolumn{4}{|l|}{ Experience (years): } \\
\hline$<12$ & 1 (Reference) & 1 (Reference) & 1 (Reference) \\
\hline $13-24$ & $-4.3(-21.8$ to 13.3$)$ & $0.99(0.89$ to 1.11$)$ & 0.96 (0.86 to 1.07$)$ \\
\hline$\geq 25$ & $-15.9(-33.3$ to -1.5$)$ & 0.88 (0.78 to 0.98$)$ & $0.86(0.76$ to 0.96$)$ \\
\hline \multicolumn{4}{|l|}{ Group size: } \\
\hline 1 provider & 1 (Reference) & 1 (Reference) & 1 (Reference) \\
\hline 2-19 providers & $9.3(-0.1$ to 18.7$)$ & $1.25(1.15$ to 1.36$)$ & $1.24(1.14$ to 1.36$)$ \\
\hline$\geq 20$ providers & $11.9(-0.4$ to 23.5$)$ & $1.21(1.10$ to 1.33$)$ & $1.22(1.11$ to 1.34$)$ \\
\hline$\%$ change in total No of procedures $\ddagger$ & $35.1(8.4$ to 61.8$)$ & $1.04(1.01$ to 1.07$)$ & 1.04 (1.01 to 1.07$)$ \\
\hline $\begin{array}{l}\text { \% change in regional prevalence } \\
\text { of carotid disease }\end{array}$ & $-21.7(-70.9$ to 27.6$)$ & 0.98 (0.62 to 1.55$)$ & 0.94 (0.59 to 1.49$)$ \\
\hline \multicolumn{4}{|l|}{ Specialty: } \\
\hline Vascular surgery & 1 (Reference) & 1 (Reference) & 1 (Reference) \\
\hline Thoracic surgery & $-4.9(-15.1$ to 5.3$)$ & 0.89 (0.83 to 0.95$)$ & $0.91(0.85$ to 0.98$)$ \\
\hline Cardiology & $-49.1(-73.6$ to -24.5$)$ & 0.09 (0.06 to 0.14$)$ & $0.11(0.07$ to 0.18$)$ \\
\hline General surgery & $-28.0(-36.4$ to -19.6$)$ & 0.55 (0.51 to 0.59$)$ & $0.59(0.55$ to 0.63$)$ \\
\hline Neurosurgery & $-18.1(-39.2$ to -0.2$)$ & $0.33(0.28$ to 0.40$)$ & $0.35(0.29$ to 0.42$)$ \\
\hline Interventional radiology & $-45.6(-67.2$ to -24.0$)$ & $0.10(0.07$ to 0.14$)$ & $0.13(0.10$ to 0.18$)$ \\
\hline Patients with symptoms & & & $1.003(1.001$ to 1.005$)$ \\
\hline Patients aged $>80$ years & & & 3.05 (2.75 to 3.39$)$ \\
\hline
\end{tabular}

${ }^{\star}$ Analyses based on linear regression.

tAnalyses based on Poisson regression. Additionally controlled for baseline procedures at start of study.

\$ $\%$ change in total number of procedures calculated for each physician during study period to control for providers approaching retirement and scaling down their practice.

General surgery (adjusted difference $-28.0 \%, 95 \%$ confidence interval $-36.4 \%$ to $-19.6 \%)$, neurosurgery $(-18.1 \%,-39.2 \%$ to $-0.2 \%)$, cardiology $(-49.1 \%,-73.6 \%$ to $-24.5 \%)$, and

interventional radiology $(-45.6 \%,-67.2 \%$ to $-24.0 \%)$ experienced higher rates of decline compared with vascular surgery. Thoracic surgery $(-4.9 \%,-15.1 \%$ to $5.3 \%)$ was the only specialty

that did not show statistically significant lower rates of decline compared with vascular surgery. 


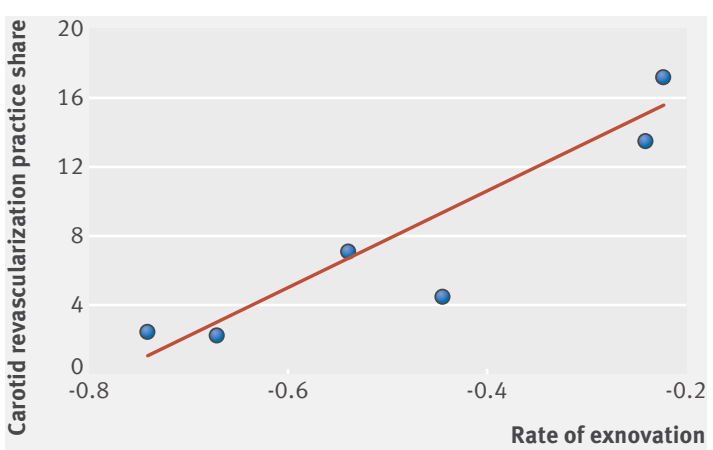

Fig 2 | Correlation of specialty practice share of carotid revascularization with risk adjusted rate of exnovation $(r=0.986, P<0.001)$

whether the percentage change in the regional prevalence of carotid disease correlated with the rates of exnovation of carotid revascularization. We did not observe a correlation of the percentage change in the regional prevalence of carotid disease with the rate of exnovation $(\rho=-0.0429, \mathrm{P}=0.760)$.

\section{Discussion}

In this study, we identified physician characteristics associated with exnovation (scaling back on use) and deadoption (abandoning use) of carotid revascularization, using a longitudinal cohort of physicians identified from Medicare claims linked to the Doximity database. Consistent with other evidence, ${ }^{20}$ we observed a declining trend in the rate of carotid revascularization nationally from 2006 to 2013 for conventional carotid endarterectomy, as well as for carotid artery stenting. We found that physicians with greater experience ( $\geq 25$ years) were likely to decline use of carotid revascularization more rapidly than those with less experience ( $\leq 12$ years). Vascular surgeons and thoracic surgeons who had the largest baseline practice share of carotid revascularizations were less likely to reduce their use of the procedure compared with their counterparts from other interventional specialties. Finally, despite evidence that patients older than 80 years as well as those without symptoms tend not to benefit from carotid revascularization, these variables were not associated with higher rates for decline of the procedure.

Although there is considerable literature on individual characteristics associated with diffusion (the process by which innovations enter everyday use), similar information about the process of exnovation and de-adoption is sparse. As well, there is considerable confusion over the nomenclature of de-adoption and exnovation, as noted by Niven et $\mathrm{al}^{2}$ and van BodegomVos et al. ${ }^{31}$ In this paper, we follow Niven et $\mathrm{al}^{2}$ in using the term de-adoption to characterize when physicians abandon a procedure and use exnovation to refer to scaling back but not abandoning a procedure. Several other surgical procedures have also exhibited a similar pattern, such as percutaneous coronary intervention following the COURAGE (Clinical Outcomes Utilizing Revascularization and Aggressive Drug Evaluation) trial, $^{32}$ and implantable cardioverter defibrillators in the recent decade. ${ }^{33}$ Van Bodegom-Vos et al $^{31}$ have introduced a third term, de-implementation, to describe when systems of healthcare (rather than individual providers) create institutional pressures to scale back on the use of specific treatments.

In an early influential study, Ryan and Gross ${ }^{34}$ described the adoption of hybrid corn by Iowan farmers. These researchers ${ }^{34}$ and others ${ }^{15}$ 35-40 found that diffusion requires an innovation, a communication process, time, and a social system. Early adopters tend to be better educated and have higher socioeconomic status. ${ }^{15}$ 35-40 They are more cosmopolite, follow the mass media, and are, or are in contact with, opinion leaders and change agents. ${ }^{15}$ 35-40 Our analysis finds some similar factors leading to early exnovation and de-adoption of procedures. Physicians who aggressively reduced use of carotid revascularization were considerably more experienced than their counterparts; this may reflect greater experience with potentially adverse outcomes after the procedure.

In some analysis, solo practitioners were more likely to reduce their use of carotid revascularization; larger groups and organizations are often more subspecialized and have robust referral patterns, creating infrastructure and inertia that may limit change. Most notably, specialties with the largest practice share of carotid revascularization at baseline were least likely to abandon the procedure. This suggests that beliefs in the value of the procedure itself may vary across specialties, as might the financial reliance on income generated from these procedures and the physician's reticence to change practice patterns. ${ }^{15}$

Rogers $^{15}$ has theoretically associated the abandonment of innovations with replacement, or disenchantment. We did not observe replacement of carotid endarterectomy by carotid artery stenting, a newer minimally invasive alternative. Clinical trials, culminating with the publication of CREST in 2010, ${ }^{29} 30$ questioned the superiority of carotid artery stenting and curbed the initial enthusiasm associated with it. ${ }^{2141-45}$

Replacement by a better alternative is, however, the most likely explanation for our exnovation model. With better options for medical management emerging in recent years, including wider use of medical treatment (such as statins and antiplatelet agents, stricter blood pressure control, and diabetic care) fewer patients may be referred for surgery. More surprisingly, recent guidelines ${ }^{27}$ recommending against carotid revascularization in patients older than 80 years did not lead to a more rapid surgical decline for these older patients, pointing against a simple explanation for disenchantment.

Prior theoretical models of discontinuance identify laggards of the diffusion process as the first to abandon an innovation. ${ }^{15}$ This does not, however, take into account the complex clinical environment, where evolving practices and new evidence fuel exnovation, driven by opinion leaders who were pioneers in adopting these procedures in the first place. ${ }^{4647} \mathrm{In}$ the context of medical exnovation and de-adoption, we speculate that laggards are both the last to adopt 
and the last to abandon an innovation. In other words, the creation of an evidence base drives adoption by pioneers, but because they have pioneer tendencies they may also be the first to scale back or abandon a procedure once the evidence base changes or something better comes along.

The present study describes an exnovation model and the physician level factors associated with it, based on the abandonment of a surgical procedure. Further investigations attempting to analyze this phenomenon should focus on the complex dynamics between physician networks. ${ }^{15}$ Referral patterns could further explain the community factors associated with exnovation of medical procedures. Studying such interpersonal relationships ${ }^{48}$ could shed light on the speed and extent to which physicians exnovate. ${ }^{15}$ Still, attempting to explain exnovation as an overall process is particularly complex. It involves an intricate interplay between technological changes, the evolving evidence base, different interpretations of evidence, interactions between physicians, the local healthcare marketplace, and possible economic impacts of adoption on healthcare.

\section{Limitations of this study}

Our analysis has several limitations. First, we observed only a cohort of physicians who in 2006-07 performed carotid revascularization. It is therefore possible that we have overstated the decline in total carotid procedures because we did not capture surgeons who began to perform carotid revascularizations after 2007 . However, the decline we observed in our physician cohort matches a recent study ${ }^{20}$ as well as findings from the Dartmouth Atlas database on rates of carotid endarterectomy, which fell from 2.5 per 1000 Medicare enrollees in 2006 to 1.6 in 2013, a decline of $36 \%{ }^{19}$

A second limitation is the descriptive nature of our data in an observational setting. To tackle potential biases, we used multiple sensitivity analyses. Third, coding inaccuracies can affect our estimates. Coding for procedures is rarely inaccurate, given that it generates revenue and is under scrutiny by payers. In addition, the current procedural terminology code for carotid artery stenting was established and widely used during the period of our study. ${ }^{25}$ Any misclassification is not expected to differentially affect individual years, and therefore the observed trends. Fourth, findings among this older, American population may not be generalizable to younger or otherwise dissimilar populations, or to beneficiaries in Medicare Advantage plans. However, a high fraction of revascularization procedures (and the majority of those at older ages) are performed in the Medicare enrollee population.

Fifth, we extracted physician characteristics from Doximity. This database relies on externally developed algorithms to match physicians to databases containing information on publications, National Institutes of Health funding, and clinical trial investigation, a process that might entail errors. ${ }^{49}$ While our measures do not capture teaching, awards, and committee service, they do have the advantage of being comprehensive-not a single physician in our Medicare sample lacked a corresponding Doximity entry. Thus our study differs from previous studies that could only speculate on physician characteristics in explaining surgical trends. $^{2141-45}$ Sixth, we acknowledge that our study of carotid revascularization is just one example and that our results may not extend to other procedures.

Finally, we were not able to determine whether surgeons made conscious choices to reduce procedures or whether primary care physicians scaled back patient referrals. Distinguishing between these two is difficult, because surgeons who are less likely to perform carotid revascularizations are less likely to receive referrals for surgery. Still, some circumstantial evidence points against primary care referrals affecting our findings-that is, the high rates of exnovation among some specialties but not others, and among more experienced surgeons. One that would necessitate that primary care physicians who refer to these types of surgeons (but not to others) are differentially more likely to reduce referrals. Although this is possible, we know of no evidence as to why this should be the case.

\section{Conclusions}

Despite extensive research on the models of diffusion of medical innovation, our understanding of the de-adoption and exnovation of established medical practices is limited. We studied this phenomenon using the example of carotid revascularization and found important differences in rates of exnovation depending on the characteristics of the physician. Those physicians who readily accept change in medical practice (early exnovators) are likely to be more experienced than those less ready to accept change, whereas late exnovators are in interventional specialties such as vascular surgery and thoracic surgery in which these procedures comprise a larger share of practice. Efforts to guide physicians in the use of treatments where the evidence is evolving toward alternatives should consider these practice factors to effectively inform change.

Contributors: KB designed the study, analyzed the data, and drafted the manuscript. JS, DG, and PG designed the study, analyzed the data, and critically revised the manuscript. KB and JS are the guarantors.

Funding: This study was supported by grants from the National Institute on Aging (PO1-AG19783), National Institutes of Health (NIH) common fund (U01-AG046830), and National Center for Advancing Translational Sciences (NCATS) of the NIH (Dartmouth Clinical and Translational Science Institute-UL1TR001086). The funders had no role in the design or execution of the study.

Competing interest: All authors have completed the ICMJE uniform disclosure form at http://www.icmje.org/coi_disclosure.pdf and declare: no support from any organization for the submitted work no financial relationships with any organizations that might have an interest in the submitted work in the previous three years, no other relationships or activities that could appear to have influenced the submitted work.

Ethical approval: This study was approved by the Dartmouth Committee for Protection of Human Subjects.

Data sharing: No additional data available.

Transparency: The guarantors (KB and JS) affirms that the manuscript is a honest, accurate, and transparent account of the study bring reported; that no important aspects of the study have been omitted; and that any discrepancies from the study as planned (and, if relevant, registered) have been explained. 
This is an Open Access article distributed in accordance with the Creative Commons Attribution Non Commercial (CC BY-NC 4.0) license, which permits others to distribute, remix, adapt, build upon this work non-commercially, and license their derivative works on different terms, provided the original work is properly cited and the use is noncommercial. See: http://creativecommons.org/licenses/by-nc/4.0/.

1 Eagle KA, Vaishnava P, Froehlich JB. Perioperative cardiovascular care for patients undergoing noncardiac surgical intervention. JAMA Intern Med 2015:175:835-9. doi:10.1001/jamainternmed.2015.0150

2 Niven DJ, Rubenfeld GD, Kramer AA, Stelfox HT. Effect of published scientific evidence on glycemic control in adult intensive care units. JAMA Intern Med 2015:175:801-9. doi:10.1001/ jamainternmed.2015.0157

3 Wang MT, Gamble G, Grey A. Responses of specialist societies to evidence for reversal of practice. JAMA Intern Med 2015;175:845-8. doi:10.1001/jamainternmed.2015.0153

4 Davidoff F. On the undiffusion of established practices. JAMA Intern Med 2015:175:809-11. doi:10.1001/jamainternmed.2015.0167

5 Rodriguez HP, Henke RM, Bibi S, Ramsay PP, Shortell SM. The Exnovation of Chronic Care Management Processes by Physician Organizations. Milbank Q 2016;94:626-53. doi:10.1111/14680009.12213

6 Greenhalgh T, Robert G, Macfarlane F, Bate P, Kyriakidou O. Diffusion of innovations in service organizations: systematic review and recommendations. Milbank Q 2004;82:581-629. doi:10.1111/ j.0887-378X.2004.00325.x

7 de Hoop E, Pols A, Romijn H. Limits to responsible innovation. J Responsib Innov 2016;3:110-34. doi:10.1080/23299460.2016.1 231396

8 Frost L, McHann J.Cleaning the closet of management innovation: The forgotten stage of exnovation. Global Business \& Economics Anthology . 2015:2:15-31

9 Sveiby KE, Gripenberg P, Segercrantz B. Challenging the innovation paradigm , Routledge, 2012.

10 Kimberly JR. Managerial Innovation. Oxford University Press, 1981.

11 Heyden DA. Governance of exnovation: phasing out non-sustainable structures. Öko-Institut e.V. Freiburg, Germany.

12 Fisher ES, Shortell SM, Savitz LA. Implementation Science: A Potential Catalyst for Delivery System Reform. JAMA 2016:315:339-40. doi:10.1001/jama.2015.17949

13 Skinner J, Chandra A. The Past and Future of the Affordable Care Act. IAMA 2016:316:497-9 doi:10.1001/jama 2016.10158

14 Roman BR, Asch DA. Faded promises: the challenge of deadopting low-value care. Ann Intern Med 2014;161:149-50. doi:10.7326/ M14-0212

15 Rogers EM. Diffusion of Innovations. 5th ed. Free Press, 2003.

16 May C. Towards a general theory of implementation. Implement Sci 2013;8:18. doi:10.1186/1748-5908-8-18

17 Grol R, Wensing M. What drives change? Barriers to and incentives for achieving evidence-based practice. Med I Aust 2004;180(Suppl):S57-60.

18 Kahneman D. Thinking Fast and Slow, Farrar, Straus \& Giroux, 2011

19 Bekelis K, Dong Z, Skinner J. Diffusion of Medical Procedures and Technology 2016 [Available from: http://www.dartmouthdiffusion. org/about.php.

20 Lichtman JH, Jones MR, Leifheit EC, et al. Carotid Endarterectomy and Carotid Artery Stenting in the US Medicare Population, 1999-2014. JAMA 2017;318:1035-46. doi:10.1001/jama.2017.12882

21 Patel MR, Greiner MA, DiMartino LD, et al. Geographic variation in carotid revascularization among Medicare beneficiaries, 2003-2006. Arch Intern Med 2010;170:1218-25. doi:10.1001/ archinternmed.2010.194

22 Tu JV, Hannan EL, Anderson GM, et al. The fall and rise of carotid endarterectomy in the United States and Canada. N Engl J Med 1998:339:1441-7. doi:10.1056/NEJM199811123392006

23 Barnett HIM, Taylor DW, Haynes RB, et al. North American Symptomatic Carotid Endarterectomy Trial Collaborators. Beneficial effect of carotid endarterectomy in symptomatic patients with highgrade carotid stenosis. N Engl / Med 1991:325:445-53.

24 Halm EA, Tuhrim S, Wang JJ, Rojas M, Hannan EL, Chassin MR Has evidence changed practice?: appropriateness of carotid endarterectomy after the clinical trials. Neurology 2007;68:187-94. doi:10.1212/01.wnl.0000251197.98197.e9

25 Goodney PP, Travis LL, Lucas FL, et al. Trends and Regional Variation in Carotid Revascularization. The Dartmouth Institute for Health Policy and Clinical Practice, 2010

26 Doximity 2016 [Available from: https://www.doximity.com/about/ companyhttps://www.doximity.com/about/company.

27 Brott TG, Halperin JL, Abbara S, et al. American College of Cardiology. American Stroke Association. American Association of Neurological Surgeons. American College of Radiology. American American College of Radiology. Society of Neurolnterventional Surgery. Society for Vascular Medicine. Society for Vascular Surgery. 2011 ASA/ACCF/ AHA/AANN/AANS/ACR/ASNR/CNS/SAIP/SCAI/SIR/SNIS/SVM/SVS guideline on the management of patients with extracranial carotid and vertebral artery disease. A report of the American College of Cardiology Foundation/American Heart Association Task Force on Practice Guidelines, and the American Stroke Association, American Association of Neuroscience Nurses, American Association of Neurological Surgeons, American College of Radiology, American Society of Neuroradiology, Congress of Neurological Surgeons, Society of Atherosclerosis Imaging and Prevention, Society for Cardiovascular Angiography and Interventions, Society of Interventional Radiology, Society of Neurolnterventional Surgery, Society for Vascular Medicine, and Society for Vascular Surgery. Circulation 2011;124:e54-130.

28 McGuire TG. Physician agency. Handbook of health economics 1, 2000:461-563

29 Brott TG, Hobson RW2nd, Howard G, et al. CREST Investigators. Stenting versus endarterectomy for treatment of carotidartery stenosis. N Engl J Med 2010;363:11-23. doi:10.1056/ NEJMoa0912321

30 McDonald IS, McDonald RJ, Fan J, Lanzino G, Kallmes DF, Cloft H]. Effect of CREST Findings on Carotid Revascularization Practice in the United States. J Stroke Cerebrovasc Dis 2015;24:1390-6. doi:10.1016/j.jstrokecerebrovasdis.2015.02.020

31 van Bodegom-Vos L, Davidoff F, Marang-van de Mheen PI. Implementation and de-implementation: two sides of the same coin?BMJ Qual Saf 2017;26:495-501. doi:10.1136/ bmjqs-2016-005473

32 Boden WE, O'Rourke RA, Teo KK, et al. COURAGE Trial Research Group. Optimal medical therapy with or without PCI for stable coronary disease. N Engl J Med 2007;356:1503-16. doi:10.1056/ NEJMoa070829

33 Patel NJ, Edla S, Deshmukh A, et al. Gender, Racial, and Health Insurance Differences in the Trend of Implantable CardioverterDefibrillator (ICD) Utilization: A United States Experience Over the Last Decade. Clin Cardiol 2016;39:63-71. doi:10.1002/clc.22496

34 Ryan B, Gross NC. The Diffusion of Hybrid Seed Corn in Two lowa Communities. Rural Sociol 1943;8:15-24.

35 Rogers EM. Categorizing the adopters of agricultural practices. Rural Sociol 1958;23:346-54.

36 Rogers EM. Rise of the classical diffusion model. Current Contents 1991;13:16.

37 Rogers EM, Dearing JW, Rao N, et al. Communication and community in a city under siege: the AIDS epidemic in San Francisco. Communic Res 1995;22:664-78doi:10.1177/009365095022006005.

38 Rogers EM, Rogers LE. A methodological analysis of adoption scales. Rural Sociol 1961;26:325-36.

39 Rogers EM, Seidel N. Diffusion of news of the terrorist attacks of September 11, 2001. Prometheus 2002;20:209-19. doi:10.1080/0810902021014326

40 Menzel H, Katz E. Social relations and innovation in the medical profession: the epidemiology of a new drug. Public Opin Q 1955;19:337-53doi:10.1086/266584.

41 Choi JH, Pile-Spellman J, Brisman JL. US nationwide trends in carotid revascularization: hospital outcome and predictors of outcome from 1998 to 2007. Acta Neurol Scand 2014;129:85-93. doi:10.1111/ ane. 12163

42 Dumont TM, Rughani Al. National trends in carotid artery revascularization surgery. J Neurosurg 2012;116:1251-7. doi:10.3171/2012.3.JNS111320

43 Eslami MH, McPhee JT, Simons JP, Schanzer A, Messina LM. National trends in utilization and postprocedure outcomes for carotid artery revascularization 2005 to 2007. J Vasc Surg 2011;53:307-15. doi:10.1016/j.jvs.2010.08.080

44 Goodney PP, Lucas FL, Travis LL, Likosky DS, Malenka DJ, Fisher ES. Changes in the use of carotid revascularization among the medicare population. Arch Surg 2008;143:170-3. doi:10.1001/ archsurg.2007.43

45 Skerritt MR, Block RC, Pearson TA, Young KC. Carotid endarterectomy and carotid artery stenting utilization trends over time. BMC Neurol 2012;12:17. doi:10.1186/1471-2377-12-17

46 Chassin MR. Explaining geographic variations. The enthusiasm hypothesis. Med Care 1993;31(Suppl):YS37-44. doi:10.1097/00005650-199305001-00006

47 Chassin MR, KosecoffJ, Park RE, et al. Does inappropriate use explain geographic variations in the use of health care services? A study of three procedures. JAMA 1987;258:2533-7. doi:10.1001/ jama.1987.03400180067028

48 Bass FM. A new product growth model for consumer durables. Manage Sci 1969;13:215-27doi:10.1287/mnsc.15.5.215.

49 Jena AB, Khullar D, Ho O, Olenski AR, Blumenthal DM. Sex Differences in Academic Rank in US Medical Schools in 2014 JAMA 2015;314:1149-58. doi:10.1001/jama.2015.10680

Supplementary information: additional tables and figure 